\title{
Rockefeller Bureaucracy and Circumknowing Science in the Mid-Twentieth Century
}

\author{
Michael J. Barany
}

HCM 7: 779-796

DOI: $10.18352 / \mathrm{hcm} .592$

\begin{abstract}
This article examines evaluation principles and techniques and their associated bureaucratic practices from the early decades of Rockefeller science philanthropy. I characterize the distinctive kinds of expertise about science that such philanthropy presumed and cultivated based on analyses of, first, documents connected to interventions in European and South American mathematics and, second, a I946 handbook prepared by Warren Weaver to guide new programme officers. Rockefeller officers developed elaborate infrastructures for understanding and intervening in the personal and institutional conditions of scientific investigation, while deliberately diverting attention away from the particulars of the science they supported. Their approach, indicative of operating strategies and assumptions for scientific funding bodies in this period, shaped access and authority across the major enterprises of late modern science, defining both what science and which scientists could benefit from new resources and opportunities.
\end{abstract}

Keywords: bureaucracy, expertise, grant administration, mathematics, philanthropy, Rockefeller Foundation 


\section{Introduction: Institutional Expertise and Scientific Funding ${ }^{1}$}

The bureaucracies of late modern scientific funding cultivated, mobilized and depended upon a distinctive form of expertise, not in science or of science, but about science. Though the officers setting policy and holding purse strings in such organizations often had advanced scientific training, and some could lay claim to notable scientific accomplishments, their work turned on knowledge about scientific people and institutions, deliberately side-lining the concepts and methodologies plied by those they funded. Their premises and procedures for assessing and intervening in scientific activity, built to a large measure on a taken-for-granted ignorance of the theoretical and technical particulars, consequentially governed who could pursue scientific research, where and how they could do so, and what they could ultimately produce.

Large American philanthropies, in interaction with professional societies and scientific institutions, defined and deployed this late modern bureaucratic expertise to fund and shape science both within the United States and internationally. They dominated especially in the decades following the Great War, when they wielded a financial and political wherewithal that would only later be eclipsed by the resources, infrastructures and prerogatives of the post-World War II military-industrialscientific complex. Norms, values and procedures imported from corporate administration and elite philanthropy furnished templates for interwar programmes of scientific funding that reconfigured scientific institutions and research programmes and established lasting models for their support and evaluation. The same figures who developed interwar philanthropic models of scientific funding went on to participate in designing and administering vast new programmes in civilian, military and non-governmental contexts. ${ }^{2}$ Reflecting in 1966 on the John Simon Guggenheim Memorial Foundation's influence, for instance, decorated chemist Willard F. Libby asserted that the foundation 'had in some respect been the model of the Atomic Energy Commission, the National Science Foundation, and probably of the National Institutes of Health too.' ${ }^{3}$ Indeed, the relatively small network of those who amassed and wielded institutional authority through the iconic giants of American scientific philanthropy often boasted the kind of access and prestige 
that made major new scientific undertakings almost unthinkable without their participation.

As the scales, means and ends of scientific funding shifted, the same problems of maintaining the kind of expertise about the people and processes of science that would enable effective interventions in scientific research itself continued to define funding bodies' operations. This article examines the social and structural assumptions built into formal and informal practices of programme administration at one dominant scientific philanthropy, the Rockefeller Foundation. Programme officers used specific forms of record-keeping to manage and apply distributed expertise about the sciences and scientists they supported. In the following sections, I offer some broad remarks on this expertise and then unpack two indicative examples of these records and their associated administrative practices for the discipline of mathematics, focusing on international funding regimes and the scale-related implications of their bureaucratic methods. I then fit these records and practices amidst the broader operating assumptions of the Rockefeller Foundation's Division of Natural Sciences at mid-century, reflected in a remarkable I946 handbook prepared by the division's director Warren Weaver.

For Rockefeller officers, formal bureaucracy underwrote highly informal approaches to grant-giving that tended to rely intensively upon prevailing biases and power structures in elite science. Such hybrid formal and informal frameworks together constituted a distinctive expertise with its own logics, blind spots and affordances that set scientific funders' perspectives apart from those of the scientific experts they consulted and evaluated. Routinized and naturalized as paperwork, these consequential means of comprehending and funding science have long outlasted the particular problems and personalities at their formation.

\section{Bureaucracy's Records}

The Rockefeller Foundation, along with associated (and varyingly independent) philanthropies with administrative or financial ties to it, has a dominant place in the historiography of scientific funding in the middle decades of the twentieth century. Sustained efforts at archival curation and research support have made the Rockefeller Foundation an especially well-studied organization, perhaps disproportionate even 
to its considerable historical importance. A bibliography maintained by the Rockefeller Archive Center lists nearly eight thousand scholarly works derived in some part from research in its collections, which include materials from a variety of significant individuals and organizations beyond the Rockefeller Foundation itself. ${ }^{4}$ Rockefeller bureaucrats' intensive and extensive custom and culture of assembling, preserving, engaging and disseminating runs simultaneously through both their organization's history and its historiography.

Although Warren Weaver began his career as a mathematician before joining the Rockefeller Foundation and maintained involvement in the discipline thereafter, mathematics was never more than a minor component in the grander scheme of the Rockefeller Foundation's portfolio of scientific programmes. The discipline has had a correspondingly small place in the foundation's historiography, most prominently represented in Reinhard Siegmund-Schultze's studies of interwar Rockefellersponsored mathematics endeavours. ${ }^{5}$ The discipline's comparatively small scale and limited material requirements (in contradistinction to higher-profile projects in areas like public health, agriculture, molecular biology or atomic physics) ${ }^{6}$ make mathematics funding a valuable window into the common habits and routines of Rockefeller operations, which can otherwise easily be lost among topic-specific ideological and technical considerations. The defining features of Rockefeller interventions in mathematics can be found, mutatis mutandis, in the background of most of its scientific undertakings.

In particular, the foundation's mathematical sponsorship underscores the nature of its officers' working distinction between knowledge about a science and knowledge of that science, with official activity and decision-making concentrated on the former expertise to the almost total exclusion of the latter. Rockefeller officers did not generally consider themselves capable of assessing the theoretical achievements or intellectual potential of prospective grantees in the discipline, and even Weaver does not appear in the archives as an expert evaluator of applicants' mathematical claims or prospects. ${ }^{7}$ I have elsewhere argued that a presumed mutual ignorance of the details of other mathematicians' work has been a central feature of mathematicians' own disciplinary practice since at least the interwar period when the discipline first became a significant target of Rockefeller philanthropy. ${ }^{8}$ Rockefeller officers' efforts to form meaningful evaluations despite the 
inaccessibility of specific research thus confronted a cognate obstacle to the period's intra-disciplinary evaluative mechanisms. Where mathematicians combined personal evaluations with new ways of bridging conceptual differences, Rockefeller officers instead focused intensively on understanding and manipulating the personal dynamics of professional scientific labour. ${ }^{9}$

This expressly subjective practice depended on a multi-layered bureaucratic system that allowed officers to form relationships in a variety of registers and from a range of subject positions. ${ }^{10}$ To succeed in fellowship and grant administration, and especially to navigate the variety of political, institutional and other obstacles Rockefeller funding recipients might face, officers worked constantly to gather and synthesize information and to solicit aid and cooperation through formal and informal channels. These, in turn, corresponded to different forms of paperwork and archival practice, including formal letters, reports, telegrams, friendly exchanges in person and by post, and official diaries. The most important decisions about programmes and funding hinged on informal, personal, deliberately subjective forms of intelligencing and evaluation. These could be effective, however, only with the support of an extensive formal bureaucratic apparatus that brought those sources of information together, emphasized some and downplayed others, and permitted concrete action based on fuzzy impressions. Thus, while paper trails must necessarily be a skew-record of the hybrid personal and bureaucratic practice of fellowship administration, organizations' operational dependence on paper apparatus allows an analysis of a wider body of activity than what appears in the archives at first glance. I have previously analyzed these formations' manifestations in Rockefeller Foundation correspondence and fellowship files and officer diaries in an essay on career Natural Sciences officer Harry Milton 'Dusty' Miller, ${ }^{\mathrm{II}}$ and here consider two other contexts.

\section{Mapping Reputation}

A small but noteworthy attempt in 1926 by Wickliffe Rose to make sense of European mathematics exhibits this constructive interplay of informal and formal expertise-work. Rose was head of the International Education Board (IEB), a Rockefeller philanthropy established in 
I923, the interventions of which in European science paved the way for undertakings on a wider scale by the Rockefeller Foundation's Division of Natural Sciences. Correspondence from I923 makes clear that, at the start of the IEB's interest in mathematics, Rose knew very little about either the mathematical profession or its principal areas of research and application. As Siegmund-Schultze documents in detail, Rose remedied this ignorance by drawing repeatedly on a small circle of leading mathematicians recruited through his connections in academic philanthropy. ${ }^{12}$ These mathematicians informed Rose's personal reconnaissance in Europe, performed their own intelligencing on his behalf, and corresponded with him on a variety of questions about the people, places and topics of mathematics.

The I926 inquiry began with a discussion between Rose and the Princeton mathematician Oswald Veblen, one of the initial mathematical informants Rose maintained since his first attempts to understand the field in I923. The two decided 'a chart of the field of mathematics' could be assembled with 'the cooperation of two or three mathematicians', and that such a chart could help guide the IEB towards the strongest centres of European mathematics. ${ }^{13}$ Accordingly, they recruited Harvard's George Birkhoff, another well-established Rose informant who had never previously visited Europe, along with Veblen's Princeton colleague, the Russian-born and Paris-raised American transplant Solomon Lefschetz, to assemble the needed information. Each listed for Rose the names, fields and locations of those European mathematicians they considered most eminent, which IEB staff accordingly assembled by 26 January into a single sorted table. ${ }^{14}$ The result reflected the contributors' biases regarding subject areas and institutions, with the field of Analysis especially well represented, and depended on general reputations rather than detailed assessments of the listed mathematicians' latest work. So respected was the towering Göttingen mathematician David Hilbert that his area of expertise appeared simply as 'all fields', while a couple other mathematicians lacked field attributions altogether.

Here, one form of paperwork (the sorted list of leaders) turned a small collection of advisory correspondence into a ready reference that enabled other kinds of analysis and application. The next item in the effort's IEB archive is a hand-marked map of Europe prepared by Ruth Savord, a librarian who came to work with the IEB by way of 
its older domestically-oriented cousin, the General Education Board. ${ }^{15}$ Savord labelled cities by name and number of mathematicians and then accented the map with red discs whose size corresponded, as the map's title explained, to the 'Relative Standing of Mathematical Centers of Europe and Number of Outstanding Men at Each'. Condensed on a single page in geographic formation, the quasi-systematic impressions of three U.S. mathematicians became an authoritative-seeming guide to the geography of mathematical excellence that could guide IEB interventions. IEB staff, in consultation with the three mathematicians, produced several iterations of this map in 1926 and I 927 , culminating in a version with the red discs replaced by pie charts subdivided into what they had by then established as the six principal branches of mathematical work in the continent.

After the initial map in the IEB archive rests a bold printed chart headed simply 'RATINGS', with cities in a single column on the left and numbers on the right, arrayed in rank order from Paris (20), Rome (I2) and Göttingen ( I I) to Strasbourg (2), Budapest (2) and Amsterdam (2). The numbers were not simply tallies of the mathematicians in the initial table and map. Rather, these ratings reflected the sum of scores Birkhoff assigned to each man according to 'his total importance for mathematics': I reflected 'solid contributions'; 2 recorded 'great depth in at least one field'; and 3 signified being 'of the first rank of importance among the mathematicians of his generation'. ${ }^{16}$ These ratings also included new information gathered on Birkhoff's first ever trip to Europe, undertaken that year with the help of a thousand-dollar IEB grant. Birkhoff extended the rating exercise to American institutions as well, though did not dare discriminate among his domestic colleagues and just assigned each a score of 2, annotating the totals to indicate that his American aggregate ratings were '[p]robably an overestimate'. Processed as a reference table for IEB use, all of Birkhoff's cautions and qualifications melted away, leaving a rank list that let one see which sites stood where in an otherwise generally inscrutable hierarchy of European mathematics.

Across one thick folder of many in the IEB's paper trail, bureaucrats deployed routine archival practices to systematize and amplify a particular kind of scientific sociality, based on the transatlantic reputations of headline figures at major institutions as viewed by a small and decidedly unrepresentative segment of the American Northeast mathematical 
elite. Such practices emphasized location, broad characterizations of disciplinary divisions and international reputation as the most important desiderata for directing IEB interventions. Though Rose consulted three of the United States' leading mathematicians for his intelligencing, he did not ask after their knowledge of mathematics as such - not methods, nor problems, nor theoretical programmes - and they knew enough not to trouble him with their mathematical expertise. Enclosing a draft map to IEB Director of Natural Sciences Augustus Trowbridge with the explanation that it was to give 'a bird's-eye view of the situation', Rose emphasized 'that no attempt has been made in the direction of mathematical accuracy' ${ }^{17}$ The kinds of scientific judgements of use to the agents of Rockefeller philanthropy depended on access to wellplaced scientific authorities, but were not the kind of judgements where scientific accuracy was a reasonable or desirable expectation.

\section{Potential in the Cards}

For individual grant and fellowship cases, where a bird's-eye view did not suffice, other forms of paperwork index officials' priorities and expertise. From first formal contact through deaccession, each fellow was the subject of an official file of application forms, records, notes and correspondence. For rapid reference, however, and for perpetual record after the initial files were no longer considered immediately useful enough to retain, each fellow also appeared on a Fellowship Recorder Card - an index card (or, frequently, a series of such cards) compactly listing relevant data and correspondence, including short excerpts of some materials from the fellow's full file accumulated as those materials arrived. As a routinely and systematically produced record of the Rockefeller funding bureaucracy, these cards give the most comprehensive and direct view of what aspects of their fellowship-related documentation mattered most when refracted through administrative judgement and procedure.

The Rockefeller Foundation's first Latin American fellow in mathematics, Rafael Laguardia of Montevideo, Uruguay, was in many respects an ideal representative of the Division of Natural Science's interventions in the region's mathematics in the I940s and I950s. He entered the division's orbit as an emerging leader of Uruguayan mathematics, 
with a stable position in Montevideo but without the wherewithal to sustain an internationally relevant research and training programme of his own. To spur Laguardia's career and strengthen Uruguayan mathematical institutions, the Rockefeller Foundation sponsored a fellowship for him to study with more established and better connected mathematicians in Rosario, Argentina, who then recommended that Laguardia continue for a further period of study in the United States. On his return to Uruguay, Laguardia led a small but now internationally relevant mathematics group, including further beneficiaries of Rockefeller and other U.S. fellowships. His relationships from Argentina and the United States gave him a foothold to become an active presence in regional and international scholarship, including hosting visiting scholars from the U.S. and representing Uruguay in the process of establishing the postwar International Mathematical Union.

Laguardia's six index cards, serially annotated front and back, show how Rockefeller officials came to see and hone him as this kind of internationally-oriented national leader. ${ }^{18}$ The top of the first card is filled with filing-related indications: Uruguay, NS (for Division of Natural Sciences), Training, 'Please Return to Fellowship Department'. Then, under the template entry for 'NAME' come his name and the years and locations of his higher education. The template then calls for his present and prospective positions, and the card records the foundation's ambition that a fellowship will help him advance from 'Prof. of Math.' to 'Dir. of the Inst. of Math. \& Statistics'. An entry for 'STUDIES' gives the initial proposed fellowship programme in Rosario, after which there is a typed-in heading for 'PROGRAM' recapitulating this with a few further details. His domestic institutional position mattered far more than his specific topics of study, which appear only insofar as they affected the kinds of mentorship and collegial relations he might obtain through the fellowship.

In a column to the right of these, the template called for Laguardia's age, marital status, number of children, fellowship dates and duration, and some financial entries. These data were the most pertinent for the Rockefeller Foundation to assess Laguardia's immediate material needs and to adjust their support accordingly. Reflecting the card's status as a diachronic reference instrument over a period where his age might increment, a forward-thinking typist later included Laguardia's year of birth next to his age. ${ }^{19}$ Together, the head material of Laguardia's 
recorder card represented, for easy reference, the vital data for his career: where he had been, where he was going, what resources and obligations he carried with him.

Beneath this front matter, the card's chronological entries began in medias res with a cable announcing that 'L. left for Rosario'. Once one was in the Rockefeller orbit, it mattered little in administrative terms how one got there, so background about contact and applications did not make it onto the card. One has to consult the officer diary from Harry Miller's I94I tour of Latin America to learn that Laguardia had been commended to him by Montevideo physics professor Walter Hill as 'the only possible candidate for the Chair of Math. Analysis', a claim Miller verified with the relevant Dean. Miller's diary also records a personal meeting with Laguardia, noting Laguardia's age, marital and family status, linguistic capabilities ('French and a very little English'), 'personally acceptable' presentation, limited research experience 'on analytical functions', and interest in a fellowship. ${ }^{20}$

The next recorder card entry documents the foundation's willingness to underwrite a calculating machine rental, an offer Laguardia declined with the explanation that his work was 'of a theoretical nature' and did not require such a device. Here was one of the few areas where subject knowledge related to fellowship administration, and the foundation's intelligencing practice - premised on navigating around subject expertise - got the matter backward. Subsequent updates note Laguardia's courses and mentorship relationships from his Rosario fellowship and one mentor's opinion that 'L. is a serious person, cultured, and intelligent' and that a renewal to study in the U.S. would raise his status 'in the eyes of his young students in Uruguay'. A note reflecting this renewal includes an excerpt of his recommendation affirming enthusiastic support for the fellowship from his Montevideo colleagues and Rosario mentor.

Beyond practical notes about stipends and travel arrangements and records of reprints and formal communications, Laguardia's recorder card dwells especially on his personality and his institutional relationships. One reads that Laguardia is 'very popular in Rosario', 'keen and competent', 'very pleasant, serious', and 'very highly regarded', often in phrases that reiterate that he is a 'young man'. Encounters with new people and places join recommendations for whom else to meet and where else to make acquaintances. Where details of Laguardia's studies 
enter, as in a note dated 25 May I944, the record emphasizes their implications for his institutional settings and interlocutors: here, 'Work in Providence would not interfere with work on the integral of Laplace because L. should be able to discuss the subject with Prof. Tamarkin (of Brown)'. The record's transcription of 'integral of Laplace', a nonidiomatic expression that is subsequently corrected as Laguardia himself spent more time in Anglophone mathematics, reflect the foundation's merely perfunctory interest in Laguardia's research. Nearly one whole side of an index card deals with the Guggenheim fellowship that Laguardia secured to extend his U.S. studies, and another addresses speculation about communist sympathies after Laguardia's return to Uruguay. ${ }^{21}$

Through the lens of the Rockefeller Foundation's bureaucracy, Laguardia manifested as a series of contacts, travels, payments and relationships, and as a collection of personal qualities and institutional potentialities, which together made him a promising recipient of the foundation's funding. While such records offered synoptic access to the mundane concerns of fellowship administration, their most important role was to give Rockefeller officers and bureaucrats a tractable way to trace and act upon fundamentally subjective and informal information about their charges. This latter kind of information had to be assembled across interviews and letters whose typical formats were poor tools for synthesis and recollection. For the dual tasks of identifying candidates with a bright future and giving them the personal and material support to realize that potential, the routine deskwork of assembling recorder cards put the necessary data at Rockefeller representatives' fingertips.

\section{Personal Qualifications}

As the Rockefeller Foundation's Division of Natural Sciences prepared to expand its officer staff in the wake of World War II, its director Warren Weaver put to print the principles of recording and evaluating implicit in the bureaucratic practices just discussed. His 1946 handbook, N.S. Notes on Officers' Techniques, defined across fifty-seven pages the delicate and consequential art of playing 'Scientific Santa Claus' as the face and authority for his iconic scientific philanthropy. ${ }^{22}$ I first encountered this handbook among the documents the foundation assembled as 
evidence of 'Operating Procedures' as background to testimony for a I952-I954 investigation in the U.S. House of Representatives targeting large tax-exempt organizations for supporting politically suspect (especially communist) activities. ${ }^{23}$ Historical reflections connected with the Rockefeller Foundation's recent centennial have brought the handbook, stamped 'Confidential', into the light, with a complete digital copy now available on the Rockefeller Archive Center's website. ${ }^{24}$ In both settings, the handbook stands as a striking illustration of programme officials' self-conception of their work on the foundation's behalf.

The bulk of the handbook is divided into two sections, on 'Negotiations with Persons or Groups Seeking Aid' and 'Comments Concerning Requests and Activities', with a coda on additional topics including personal conduct and 'Unity of the RF'. Roughly, the 'Negotiations' section concerns how to interact with prospective grant recipients so as to gain the information needed for sound administration while minimizing potential complications or the appearance of bias, while the 'Comments' section lays out principles for what makes an effective use of Rockefeller resources. A division's staff had 'the obligation to keep itself widely and intimately informed concerning the personnel and opportunities within the areas of program interest', letting them fit people to prospects in allocating funds. ${ }^{25}$ Across the sections, Weaver devotes sustained attention to the core bureaucratic problem considered in this essay, of converting informal relationships and assessments into reliable records to support funding activity.

This meant, according to Weaver, that 'officers should, in the language of radiation theory, be good absorbers and very poor emitters', assiduously collecting scientists' testimony without giving anyone the impression of having special access or committing 'the professorial sin of lecturing the visitor concerning the RF, science, and the world in general. ${ }^{26}$ Individual scientists, Weaver asserted, were not likely to be straightforwardly reliable informants on their own. Some were 'very good salesmen' or 'very poor salesmen', many were uncomfortable talking about money, and written recommendations or other direct evaluations of one scientist by another were categorically cause for scepticism. ${ }^{27}$ Rather, with 'a lot of time and patience and energy', an officer should seek information by 'slowly building up a relationship of close confidence with a large number of shrewd and hardheaded scientists; and talking with them about young men so continuously and generally 
that we build up in our own files an inter-locked web of objective and dependable information. ${ }^{28}$ Ask enough people over a long enough time and eventually 'some dependable facts emerge out of the fog. ${ }^{29}$

The essential instrument for accumulating the raw data out of which useful information might emerge was the 'old, proven, and treasured tradition' of preparing 'diary accounts of all interviews of any importance, and of trips', which were to be succinct, clear, accurate and complete. Weaver explained that 'Diaries are specially important to us because of our great reliance on conversations ... and on travel for firsthand impressions as contrasted with buying out of a catalogue. ${ }^{30}$ There follow a series of guidelines for making such first-hand impressions as genuine and valuable as possible, from how to pose questions to what to spend on meals. An officer might 'visit, on trips, a scientist in his own home' and should try to 'Talk with fellowship candidates in their own labs, sitting on stools and smoking with them' ${ }^{31}$

Informal, personal interaction gave officers access to 'What we are really interested in', namely, 'men and ideas', or more precisely 'the training and development of such men as give promise of producing important ideas'. Officers were to use funding for 'drawing young men into the field' and supporting senior scholars 'who attract and inspire young men'. Therefore, Weaver explained, 'we think it is necessary and proper to be interested in the personal qualifications (as opposed to the intellectual qualifications) of fellowship candidates. ${ }^{32}$ Candidates must show 'promise for leadership', which meant funding fellows who already had 'a good post to which they can return', relying on established senior figures to recommend up-and-coming ones, and taking precautions to ensure the fellow could quickly benefit from a placement and also quickly return home. ${ }^{33}$ This logic extended to the fields the foundation financed. Those with strong commercial ties or 'rich uncles in business' had other patrons who could shape the field and its leadership, diminishing the value of Rockefeller patronage. ${ }^{34}$

Focusing on leadership became a license to follow the biases and prejudices of the sciences and societies in which officers intervened. 'Questions of race, color, religion, and politics are of themselves totally irrelevant ... [nor] whether a candidate is hunchbacked or handsome' claimed Weaver before qualifying the claim with a tell-tale 'but'. 'But we $d o$ care if any circumstance arising out of such otherwise irrelevant factors threatens to handicap or circumscribe the effectiveness of the 
candidate as a future leader in science.' 35 It was not the foundation's place to rectify inequities of opportunity, and if prejudice made some candidates more likely to succeed than others then the sound investment would be on the candidates so favoured. That is, race, colour, religion and politics were eminently relevant. The foundation's records reflect these preoccupations in precisely the terms of Weaver's dismissal, externalizing culpability for these blameworthy assessments by insisting that they mattered only to the extent the rest of the world was not so tolerant as a Rockefeller officer. The same reasoning justified holding women to 'a considerably stronger than average' standard to account for the 'sizable fraction' who 'will work a few years and then marry and stop.' ${ }^{36}$

\section{Conclusion: Circumknowing and Circumscribing}

The Division of Natural Science's approach to evaluating scientists, and the bureaucratic systems that underwrote it, served to take the complicated and subjective institutions of science and collapse them into the 'yes', 'no' and 'how much' of grant making. Officers were to embrace the fog and fuzziness of science in their fact finding, but produce records that banished equivocation. For Weaver, 'the question "May I have this fellowship?" ought to be like the questions "Is this egg fresh?" or "Do you love me?".' Any hesitation meant 'the answer is surely no.' 37

The solution, in part, was to leave the science to the scientists. Officers pursued forms of intelligencing and documentation that yielded useful knowledge about science while largely avoiding scientific questions themselves. Both expertise and infrastructure took distinctive forms in the mid-twentieth century as officers grappled with how to know scientific institutions from the outside. Such circumknowledge of science, built on intensively cultivated expertise about scientific institutions and personnel, let officers circumscribe irresoluble questions about the future of scientific knowledge by training their attention on its conditions of production. Even iconic examples of funding bodies intervening in the specific content of scientific theories can be understood foremost as institutional interventions rooted in circumscientific knowledge. Thus, Weaver's famous effort to promote molecular biology hinged fundamentally on his expertise regarding relationships between research and researchers in the mathematical, physical and biological sciences, rather than a special scientific insight into biology. ${ }^{38}$ 
Circumscientific knowledge became an especially important means of cutting through the disciplinary tangle of late modern scientific research, divided by specialization and reconfigured by applications and interdisciplinarities. Using institutional change as a proxy for scientific change, funders could play a role in the latter's redistribution of resources and opportunity structures by observing and acting on the former. One cost of this approach was a lack of critical purchase on the institutions they underwrote. Unable to tell with confidence what institutional successes came from scientific excellence (whatever that might mean) and what came from the cumulative effects of bias and prejudice, officers had little choice but to treat all successes as of the same kind. Young, male scientists ensconced in already-influential disciplinary networks looked poised to lead, because that was how leaders of their disciplines had always looked: an institutional Matthew Effect. ${ }^{39}$ Conversely, critical questions about accountability and the ethical and social implications of research that had long been excluded from elite evaluations of science had few places to enter.

Science funding is a necessarily speculative enterprise. Its latemodern apparatus, honed through the bureaucratic practice of towering philanthropies, defined what futures were available on the basis of funders' circumscribed means of comprehending their present. Their funding infrastructures came embedded in broader infrastructures for supporting health, the arts and other social goods. The history of science funding is part of a broader history of achievements and failures of social perception redounding to achievements and failures of possibility. In each manifestation, people's and institutions' circumscribed capacity to understand each other, when passed through the means and operation of pecuniary power, buttressed a circumscribed future.

\section{Notes}

I The author wishes to thank Margaret Hogan Snyder, John Krige, Reinhard Siegmund-Schultze, the organizers and participants in the conference on Funding Bodies in Late Modern Science, and this article's referees for their valuable contributions and criticisms.

2 E.g. Inderjeet Parmar, Foundations of the American Century: The Ford, Carnegie, and Rockefeller Foundations and the Rise of American Power 
(New York, 2012); John Krige, American Hegemony and the Postwar Reconstruction of Science in Europe (Cambridge, MA, 2006); Mark Solovey, Shaky Foundations: The Politics-Patronage-Social Science Nexus in Cold War America (New Brunswick, NJ, 20I3), Daniel J. Kevles, The Physicists: The History of a Scientific Community in Modern America (New York, 1978).

3 'Confidential Report on a Joint Dinner of the Board of Trustees and the Committee of Selection Held io February I 966 at the Century Association', Io, Henry A. Moe Papers, 'Guggenheim Foundation - John Simon Memorial' folder 37, American Philosophical Society, Philadelphia, PA.

4 'Bibliography of Scholarship at the Rockefeller Archive Center'; https:// www.zotero.org/groups/22265o/rac/items/ (accessed 2019).

5 Most prominently, Reinhard Siegmund-Schultze, Rockefeller and the Internationalization of Mathematics Between the Two World Wars: Documents and Studies for the Social History of Mathematics in the 2oth Century (Basel, 200I).

6 E.g. Marcos Cueto (ed.), Missionaries of Science: The Rockefeller Foundation and Latin America (Bloomington, 1994); John H. Perkins, Geopolitics and the Green Revolution: Wheat, Genes, and the Cold War (Oxford, I997); Lily E. Kay, The Molecular Vision of Life: Caltech, the Rockefeller Foundation, and the Rise of the New Biology (Oxford, 1993); Angela N.H. Creager, Life Atomic: A History of Radioisotopes in Science and Medicine (Chicago, 20I3).

7 There is a vast science studies literature, beyond the scope of this essay, examining differential expertise in contexts of scientific research. This, in turn, draws on a still larger anthropological literature on empathy, knowledge and cultural legibility in fieldwork. A relatively concise explanation of the central issues for studies of contemporary scientists, from the perspective of the ethnographic researcher rather than the philanthropic officer (though the comparison is suggestive), is Harry Collins, 'How Do You Know You've Alternated', Social Studies of Science 34:I (2004), I03-6.

8 Michael J. Barany and Donald MacKenzie, 'Chalk: Materials and Concepts in Mathematics Research', Catelijne Coopmans, Michael E. Lynch, Janet Vertesi and Steve Woolgar (eds) Representation in Scientific Practice Revisited (Cambridge, MA, 2014), I07-29; Michael J. Barany, 'Integration by Parts: Wordplay, Abuses of Language, and Modern Mathematical Theory on the Move', Historical Studies in the Natural Sciences 48:3 (2018), 259-99. 
9 Michael J. Barany, 'Fellow Travelers and Traveling Fellows: The Intercontinental Shaping of Modern Mathematics in Mid-Twentieth Century Latin America', Historical Studies in the Natural Sciences 46:5 (2016) 669-709.

Io Michael J. Barany, 'The Officer's Three Names: The Formal, Familiar, and Bureaucratic in the Transnational History of Scientific Fellowships', John Krige (ed.), How Knowledge Moves: Writing the Transnational History of Science and Technology (Chicago, 20I9), 254-80. On the broader history of bureaucracy and administrative expertise in connection with science, see Jon Agar, The Government Machine: A Revolutionary History of the Computer (Cambridge, MA, 2003); Peter Becker and William Clark (eds), Little Tools of Knowledge: Historical Essays on Academic and Bureaucratic Practices (Ann Arbor, MI, 200I); Theodore M. Porter, 'How Science Became Technical', Isis I00:2 (2009) 292-309; Hunter Heyck, 'The Organizational Revolution and the Human Sciences', Isis I05 (20I4), I-3 I; Michael Zakim, Accounting for Capitalism: The World the Clerk Made (Chicago, 2018).

I I Barany, 'Three Names'.

I2 Siegmund-Schultze, Rockefeller, 27-56. On the example discussed here, see $43-5$.

I3 Rose to Birkhoff, I I January I926, International Education Board (hereafter IEB), box 8, folder I Io, Rockefeller Archive Center, Sleepy Hollow, NY (hereafter RAC).

I4 'Leaders in the Field of Mathematics Listed Under Countries and Institutions', 26 January I926. IEB, box 8, folder I Io.

I5 Ellen Prokop, 'Ruth Savord', Wikipedia: The Free Encyclopedia; https:// en.wikipedia.org/w/index.php?title=Ruth_Savord\&oldid=6509 I I 558, March 2015 (accessed 20I8).

I6 Birkhoff to Rose, 7 November I926, IEB, box 8, folder I Io.

I7 Rose to Trowbridge, 6 July I926, IEB, box 8, folder I Io.

I 8 RAC, Rockefeller Foundation records, Record Group I0.2, Fellowship recorder cards, box I8, 'Uruguay: Laguardia (Carle), Mr. Rafael' .

I9 The spacing and type make clear that the year was added on a different typewriter at a later point, possibly coinciding with the typed annotation of Laguardia's fellowship renewal.

20 'Latin America, Diary of Visit by Harry M. Miller, July 28 - November 26, I94 I', Sept. I-4, I94I (p. 63), RAC, Rockefeller Foundation records, general correspondence, Record Group 2, I940-I946 (FA758), subgroup I94I, series I94I/300.D, Box 56I. 
2I On these political speculations and their relation to programme administration, see Barany, 'Three Names'.

22 Warren Weaver, N.S. Notes on Officers' Techniques, Rockefeller Foundation, I946; https://rockfound.rockarch.org/digital-library-listing/-/ asset_publisher/yYxpQfeI4W8N/content/n-s-notes-on-officers-techniques (accessed 20I8). Quotation on page 4.

23 RAC, RF, Cox and Reece Investigations (FA4I 8), series 3, Box 5I, folder 862.

24 See Eric John Abrahamson, Beyond Charity: A Century of Philanthropic Innovation (New York, 2013), I84-203.

25 Weaver, Officers' Techniques, 24.

26 Ibid., 2.

27 Ibid., 5-6, 20-I.

28 Ibid., 20.

29 Ibid., 2 I.

30 Ibid., I3.

3 I Ibid., I5, I7.

32 Ibid, 29.

33 Ibid., 32-3.

34 Ibid., 43.

35 Ibid., 32. Emphasis in original.

36 Ibid., 30.

37 Ibid., 33.

38 See Kay, Molecular Vision; cf. Heyck, 'Organizational Revolution'.

39 Margaret W. Rossiter, 'The Matthew Matilda Effect in Science', Social Studies of Science 23:2 (I993), 325-4I.

\section{About the Author}

Michael J. Barany is Lecturer in the History of Science at the University of Edinburgh. His current research focuses on the history of globalization and the institutional, infrastructural, and intellectual transformations of the modern discipline of mathematics. His writing on the history, sociology and culture of modern science and mathematics can be found at his website, http://mbarany.com. The research reported here was supported in part by the Dartmouth College Society of Fellows and was written in part while the author was supported by National Science Foundation Grant No. SES I82689I. E-mail:michael@mbarany.com 